\title{
Taction thresholds for short pulses'
}

RONALD T. VERRILLO

LABORATORY OF SENSORY COMMUNICATION, SYRACUSE UNIVERSITY

Absolute taction thresholds for short pulses are determined for different pulse-repetition rates and sizes of contactor. It is shown that cutareous mechanoreceptors summate energy increments resulting from an increase in repetition rate and in the size of the contactor. Discrepancies between measurements obtained using short pulses and sine waves are discussed. The results are consistent with the hypothesis that a duplex mechanism of mechanoreception exists over most of the body surface.

The absolute thresholds for vibration, measured as a function of sinusoidal frequencies, have been established for human skin (Békésy, 1939; Hugony, 1935; Knudsen, 1928; Setzepfand, 1935; Sherrick, 1953; Verrillo, 1963). The general shape of the function is U-shaped with a minimum in the region of $250 \mathrm{cps}$. Variations in threshold as a function of contactor size (Verrillo, 1963) and for a variety of temporal patterns of the stimulus have also been determined (Verrillo, 1965). Since the frequency characteristics of the threshold is determined not only by events per unit of time, but also by the rise time and duration of the individual event, it becomes important to examine the threshold function using short pulses of constant rise time and pulse width in lieu of sinusoidal vibrations. A number of different contactor sizes were tested to examine the effects of spatial summation.

\section{Apparatus and Procedure}

The apparatus and experimental procedures used in this experiment are described in an earlier publication (Verrillo, 1965). Rectangular electrical pulses of 1.0 msec. duration were passed through a manual attenuator and power amplifier and fed to a vibrator. The response of the vibrator to this signal was a highly damped oscillation with a width of $1.0 \mathrm{msec}$, and 1.0 msec, rise time.

The Ss were tested in a booth that provided isolation from building vibrations and wore earmuffs to eliminate sounds from the vibration. The site of testing was on the fleshy pad over the first metacarpal (palmar) of the right hand.

\section{Threshold as a Function of Repetition Rate}

Absolute taction thresholds were determined as a function of pulses repeated at the rate of $1,2,4,9,17$, $32,64,130$, and 200 per sec. Interference between pulse transients made it impossible to test at higher rates. In order to assess the effect of contactor area, four areas were used: $0.005,0.02,0.32$, and $2.9 \mathrm{~cm}^{2}$.

The experimental results shown in Fig. 1 are plotted as a function of pulse repetition rate. Each data point represents the median of three testing sessions using four Ss. Curves have been drawn through some of the data to indicate the slope. It is evident that for the two

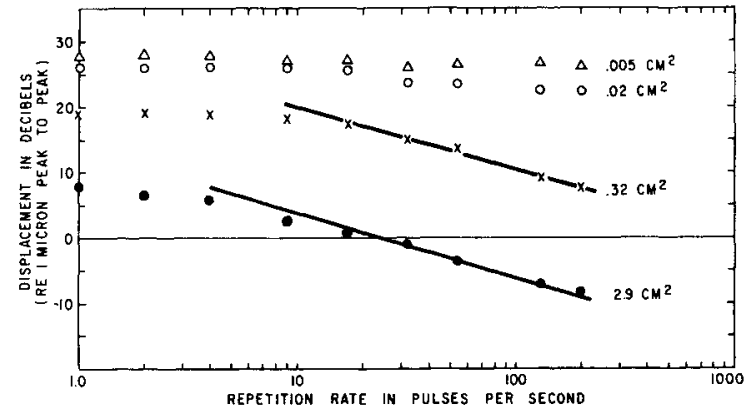

Fig. 1. Vibrotactile thresholds as a function of pulse repetition rate with contactor area as parameter.

large contactors $\left(0.32\right.$ and $\left.2.9 \mathrm{~cm}^{2}\right)$ the skin is summating the energy over pulse rate. The slope is $-3 \mathrm{~dB}$ per doubling of the repetition rate. This curve is consistent with the slope predicted by Zwislocki's theory of temporal summation accounts for $3 \mathrm{~dB}$ of the $12 \mathrm{~dB}$ slope found below $250 \mathrm{cps}$ in the threshold curve for sinusoidal vibrations (Verrillo, 1963).

It is also evident that for small contactors (.02 and $.005 \mathrm{~cm}^{2}$ ) there is no summation over pulse repetition rate. This flat curve was also observed when thresholds using small contactors were plotted as a function of sinusoidal frequencies (Verrillo, 1963). The difference in threshold response between large and small contactors has been explained by a dual-receptor hypothesis of mechanoreception in cutaneous tissue (Verrillo, 1963; Verrillo, 1966). This hypothesis states that one receptor system summates energy as frequency increases while the other functions independent of frequency. The data in Fig. 1 support this hypothesis. Threshold as a Function of Contactor Size.

The data are replotted in Fig. 2 as a function of contactor size with repetition rate as parameter. The

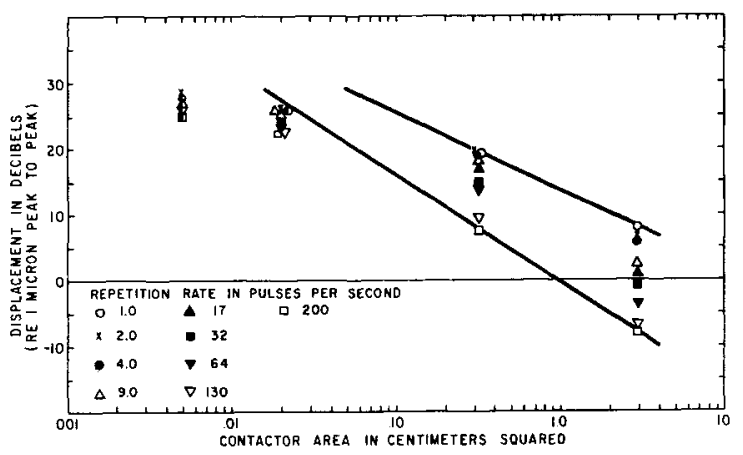

Fig. 2. Vibrotactile thresholds as a function of contactor area with repetition rate as parameter. 


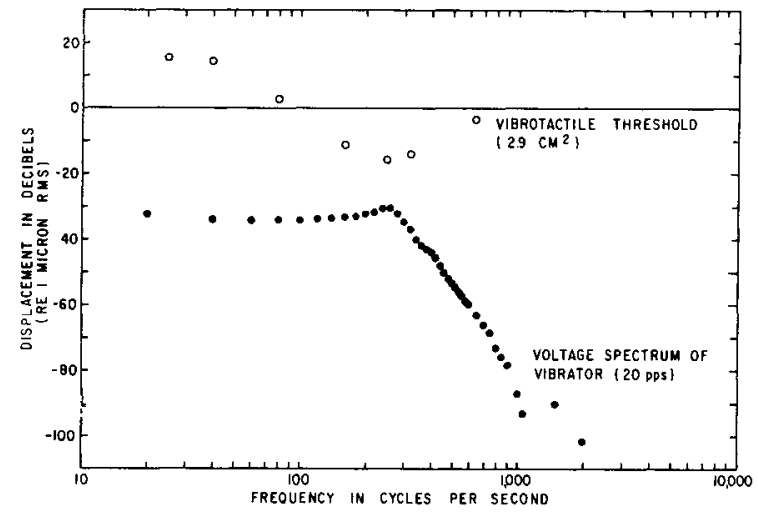

Fig. 3. Voltage spectrum of short pulses repeated at the rate of 20 per second and the vibrotactile threshold for a $2.9 \mathrm{~cm}^{2}$ contactor.

data show that the skin receptors summate energy over the area of the stimulus at all pulse repetition rates. Comparison of these data with results of a similar experiment in which sinusoidal frequencies were used (Verrillo, 1963) reveal a very obvious difference. For sinewaves no spatial summation occurs for the lowest frequencies (25 and $40 \mathrm{cps}$ ) whereas the pulse data in Fig. 2 show spatial summation even at $1 \mathrm{pps}$. This at first appears to be inconsistent with the duplex hypothesis which would require that one population of receptors be independent of spatial and temporal changes.

In order to examine this result more closely, spectral analyses of the pulses were made at three repetition rates. This analysis showed that the envelopes of the

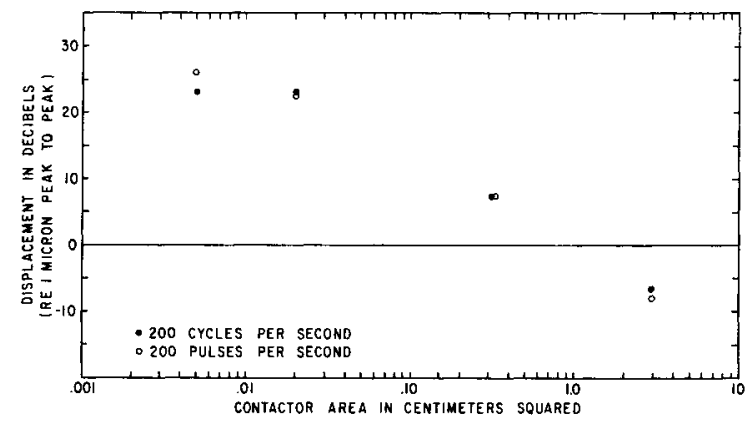

Fig. 4. Vibrotactile thresholds for sinusoidal vibrations (200 cps) and for short pulses (200 pps) plotted as a function of contactor area. pulse spectra are essentially flat to $250 \mathrm{cps}$ where there is a slight rise and then a steep cut-off to 1000 cps. A pulse spectrum, produced by a repetition rate of $20 \mathrm{pps}$, and the absolute vibrotactile threshold for a $2.9 \mathrm{~cm}^{2}$ contactor are shown in Fig. 3. The region of greatest sensitivity for the skin $(250 \mathrm{cps})$ is coincident with those frequency components of the pulse having the greatest amplitude. This is substantiated further by comparing the threshold data for $200 \mathrm{cps}$ with the corresponding results of a repetition rate of 200 pps (Fig. 4). Although the slopes in Fig. 2 for 1 through 32 pps are of low repetition rate, the pulses have strong components in the region of $250 \mathrm{cps}$ which determine the threshold and thus the downward deflection of the curve.

Another discrepancy between sinusoidal and pulsed data deserves mentioning. The slopes in Fig. 2 vary about $-4 \mathrm{~dB}$ per doubling of the area while the corresponding sine-wave slopes are about $-3 \mathrm{~dB}$ per doubling (Verrillo, 1963). This difference may be attributed to the fact that the curves for the sinusoidal results are based on four data points, while the curves in Fig. 2 are based on but two points. Referring again to Fig. 4 it can be seen that when the same number of points are used for both sinusoidal and pulsed data, the slopes are identical. It is evident that the threshold for vibration decreases in direct proportion to the stimulus area regardless of the shape of the individual stimulus event.

\section{References}

Bekésy, G. von Über die Vibrationsempfindung, AKJST $Z, 1939$ 4, 316-334.

Hugony, A. Über die Empfindung von Schwingungen mettels des Tastsinnes. Z. Biol., 1935, 96, 548-553.

Knudsen, V. o. "Hearing" with the sense of touch. J. gen. Psychol., 1928, 1, 320-352.

Setzepfand, $W$. Frequenzabhangigkeit der Vibrationsempfindung des Menschen. Z. Biol., 1935, 96, 236-240.

Sherrick, C. E., Ir. Variables affecting sensitivity of the human skin to mechanical vibration. J. exp. Psychol., 1953, 45, 273282.

Verrillo, R. T. Effect of contactor area on the vibrotactile threshold. J. Acoust. Soc. Amer., 1963, 35, 1962-1966.

Verrillo, R. T. Temporal summation in vibrotactile sensitivity. J. Acoust. Soc. Amer., 1965, 37, 843-846.

Zwislocki, J. Theory of temporal summation. J. Acoust. Soc. Amer, 1960, 32, 1046-1060.

\section{Note}

1. This work was supported by a contract between the U. S. Office of Naval Research and Syracuse University. 